disorders, as well as those with lesser degrees of disturbed eating, merit specialised help. Treatment approaches that deal with both the behaviour and attitudes characteristic of these patients seem to show promise. ${ }^{25} 26$

We thank the staff and patients of the Young Adult Diabetic Clinic at the John Radcliffe Hospital in Oxford for their help with this study and the general practitioners who gave us access to their case registers. Sarah Beglin helped greatly in generating data on the control sample. The study was supported by a project grant from the Mental Health Foundation (to RAM and CGF) and a programme grant from the Wellcome Trust (to CGF). RCP was supported by a Wellcome Trust Research training fellowship in mental health. CGF is a Wellcome Trust senior lecturer. This paper was prepared while CGF was a fellow at the Center for Advanced Study in the Behavioral Sciences at Stanford Support for this fellowship was provided by the MacArthur Foundation and the Foundations Fund for Research in Psychiatry Endowment.

1 Rodin GM, Daneman D, Johnson LE, Kenshole A, Garfinkel P. Anorexia mellitus: a systematic study. 7 Psychiat Res $1985 \cdot 19 \cdot 381-4$

2 Wing RR, Nowalk MP, Marcus MD, Koeske R, Finegold D. Subclinical eating disorders and glycemic control in adolescents with type I diabetes. Diabetes Care 1986;9:162-7.

3 Steel JM, Young RJ, Lloyd GG, Clarke BF. Clinically apparent eating disorders in young diabetic women: associations with painful neuropathy and other complications. BMF 1987;294:859-62.

4 Steel JM, Young RJ, Lloyd GG, MacIntyre CCA. Abnormal eating attitudes in young insulin-dependent diabetics. Brf P sychiatry 1989;155:515-21.

Fairburn CG, Beglin SJ. Studies of the epidemiology of bulimia nervosa. A $m$ F Psychiatry 1990;147:401-8.

New York: Guilford Press, 1990.

7 Szmukler GI, Russell GFM. Diabetes mellitus, anorexia nervosa and bulimia. Brf Psychiatry 1983;142:305-8.
8 Szmukler GI. Anorexia nervosa and bulimia in diabetes. 7 Psychosom Re's 984;28:365-9.

9 Mayou RA, Peveler RC, Davies B, Mann JI, Fairburn CG. Psychiatric morbidity in young adults with insulin-dependent diabetes mellitus. Psychol Med (in press)

10 Copper Z, Fairburn $\mathrm{CG}$. The eating disorder examination: a semi-structured interview for the assessment of the specific psychopathology of eating disorders. Int 7 Euting Disorders 1987:6:1-8.

11 Cooper Z, Cooper PJ, Fairburn CG. The validity of the eating disorder examination and its subscales. Br. F Psychiatry 1989;154:807-12.

12 Wilson GT, Smith D. Assessment of bulimia nervosa: an evaluation of the eating disorder examination. Int $\mathcal{F}$ Eating Disorders 1989;8:173-9.

13 Rosen JC, Vara L, Wendt S, Leitenberg H. Validity studies of the eating disorder examination. Int $\mathcal{f}$ Eating Disorders 1990;9:519-28.

14 Garner DM, Olmsted MP, Bohr Y, Garfinkel PE. The eating attitudes test: psychometric features and clinical correlates. Psychol Med 1982;12:871-8.

15 Nathan DM, Singer DE, Hurxthal K, Goodson JD. The clinical information value of the glycosylated haemoglobin assay. $N$ Engl f Med 1984;310:341-6. 16 Fleiss JL. Statistical methods for rates and proportions. New York: Wiley, 1981. 17 American Psychiatric Association. Diagnostic and statistical manual of mental disorders. Third edition, revised (DSM-III-R). Washington, DC: APA, 1987.

18 Robertson P, Rosenvinge JH. Insulin-dependent diabetes mellitus: a risk factor in anorexia nervosa or bulimia nervosa? An empirical study of 116 women. F Psychosom Res 1990;34:535-41.

19 Hudson JI, Wentworth SM, Hudson MS, Pope HG. Prevalence of anorexia nervosa and bulimia among young diabetic women. $f$ Clin Psychiatry $1985 ; 46: 88-9$.

20 Rosmark B, Berne C, Holmgren S, Lago C, Renholm G, Sohlberg S. Eating disorders in patients with insulin-dependent diabetes mellitus. f Clin Psychiatry 1986;47:547-50.

21 Fairburn CG, Steel JM. Anorexia nervosa in diabetes mellitus. $B M \mathcal{J}$ 1980;280:1167-8.

22 Hillard JR, Hillard PJA. Bulimia, anorexia nervosa and diabetes-deadly combinations. Psychiatr Clin North Am 1984;7:367-79.

$23 \mathrm{La}$ Greca AM, Schwarz LT, Satin W. Eating patterns in young women with IDDM: another look Diabetes Care 1987:10:659-60.

24 Kaminer Y, Robbins DR. Insulin misuse: a review of an overlooked psychiatric problem. Psychosomatics 1989;30:19-24

25 Peveler RC, Fairburn CG. Anorexia nervosa in association with diabetes mellitus: a cognitive-behavioural approach to treatment. Behaviour Research und Therapy 1989:27:95-9.

26 Peveler RC, Fairburn CG. The treatment of bulimia nervosa in patients with diabetes mellitus. Int $\mathcal{F}$ Eating Disorders (in press).

(Accepted 25 April 1991)
Department of Surgery,

University of Aberdeen

Eleri L Cusick, FRCSED,

research fellow

Zygmunt H Krukowski,

FRCSED, consultant surgeon

Carol A MacIntosh, FRCSED,

research fellow

Norman A Matheson,

FRCSED, consultant surgeon

Correspondence to:

MrN A Matheson, Ward 49,

Aberdeen Royal Infirmary,

Foresterhill, Aberdeen

AB9 2ZB.

BMF 1991;303:20-2

\title{
Risk of neoplasia and malignancy in "dominant" thyroid swellings
}

\section{Eleri L Cusick, Zygmunt H Krukowski, Carol A MacIntosh, Norman A Matheson}

\begin{abstract}
Objective-To determine the risk of neoplasia and malignancy in "dominant" thyroid swellings.

Design-Prospective analysis during six years.

Setting-Thyroid clinic serving the Grampian region.

Patients -574 consecutive patients presenting with a discrete thyroid swelling, of whom $179(31 \%)$ were classified clinically as having a dominant area of enlargement within a multinodular gland.

Results-After clinical and cytological assessment 77 dominant swellings were excised. Of the excised swellings, 45 were non-neoplastic and 32 neoplastic, including 11 malignant lesions. The minimum incidence of neoplasia and malignancy in all 179 dominant swellings was therefore $18 \%$ and $6 \%$ respectively.
\end{abstract}

Conclusion-Dominant thyroid swellings should be regarded with greater clinical suspicion than has been traditional.

\section{Introduction}

Although thyroid swellings are common and most are benign, there is a substantial incidence of malignancy in isolated (solitary) swellings, usually quoted at about $20-30 \% .^{1-4}$ Swellings associated with clinically palpable generalised abnormality of the thyroid are generally regarded with much less suspicion. In 1983 Beierwaltes stated, "If palpation reveals palpable enlargement of the ipsilateral lobe containing the nodule and of the opposite lobe also, the probability of the lesion being malignant decreases from $35-45 \%$ range to less than $1 \%$."
To distinguish swellings associated with (and presumably, in pathological terms, most likely part of a generalised thyroid abnormality from clinically isolated swellings we have termed them dominant thyroid swellings. Previously the term dominant has apparently been used neither precisely nor consistently, and some authors use it interchangeably with solitary nodule $^{6}$ or do not distinguish between isolated and dominant swellings in analysing data. ${ }^{\text {? }}$

\section{Patients and methods}

During six years (September 1981 to August 1987) all patients referred with a thyroid swelling to the surgical team at a joint medical and surgical thyroid clinic were entered into a prospective study. On the basis of clinical examination swellings were classified as isolated, dominant, or generalised. A discrete swelling was termed isolated if the thyroid was otherwise impalpable and dominant if there was evidence of a generalised abnormality, usually in the form of a palpable nodularity or enlargement of the contralateral lobe.

Fine needle aspiration cytology and histology-Fine needle aspiration cytology was performed routinely in the outpatient clinic as described ${ }^{8}$ : that paper also gave details of cytological and histological interpretation and data handling.

Terminology and indications for operation - The term neoplastic embraces all follicular neoplasms as well as malignant lesions. According to histological criteria most follicular neoplasms are apparently benign, but careful histological study is the only means of detecting invasive features on which the differentiation between 
adenoma and carcinoma is based. In addition, it may be biologically unsound to categorise follicular neoplasms as benign and malignant. ${ }^{9}$ Our management aim was therefore to remove all neoplastic swellings. All swellings reported cytologically as malignant or possibly neoplastic, even if on only one of several aspirates, were excised. When the cytological picture was non-neoplastic a decision to operate. was based on known clinical risk factors such as age, male sex, increase in size, and associated lymphadenopathy. We were also influenced by size, consistency, retrosternal extension, tracheal deviation and compression, and the patient's wishes. The inconvenience, according to distance, of continuing review and repeated aspiration was also a consideration, especially in patients from Orkney and Shetland.

\section{Results}

During six years 574 patients presented with discrete thyroid swellings, of which $179(31 \%)$ were classified clinically as dominant and $395(69 \%)$ as isolated. The isolated swellings were the subject of a separate paper with emphasis on the accuracy of cytology.$^{8}$ Of the patients with dominant swellings, $167(93 \%)$ were women and $12(7 \%)$ men. Their modal age group was 50-60 years (median 51, range 18-82), and the modal swelling size was $2-4 \mathrm{~cm}$ in diameter. After clinical and cytological assessment 77 patients (43\%) (71 women, six men) had the swelling excised.

Of the 77 excised swellings, 45 were non-neoplastic and 32 neoplastic, including eight malignant lesions (three papillary carcinomas, three follicular carcinomas, two lymphomas) and three occult carcinomas. Two of these were 0.7 and $1.0 \mathrm{~cm}$ in diameter and separate from the dominant mass; the third showed a small area of papillary change within a cystic swelling and was considered equivalent to occult carcinoma. The remaining 21 neoplasms were follicular adenomas (table I).

TABLE I-Histological findings in 77 resected dominant thyroid swellings

\begin{tabular}{lc}
\hline Histological findings & $\begin{array}{c}\text { No of } \\
\text { patients }\end{array}$ \\
\hline Colloid degeneration & 25 \\
Colloid adenoma & 13 \\
Chronic lymphocytic thyroiditis & 7 \\
Follicular adenoma & 21 \\
Occult carcinoma & 3 \\
Malignant (papillary 3, follicular 3, lymphoma 2) & 8 \\
\hline
\end{tabular}

In six of the eight malignant lesions there was evidence of chronic lymphocytic thyroiditis (autoimmune thyroiditis, Hashimoto's disease). Both lymphomas were associated with thyroiditis, previously diagnosed in one case and evident histologically in the other. Adjacent thyroid tissue showed histological changes of thyroiditis in two of the three papillary carcinomas and one of the three follicular carcinomas (the microsomal autoantibody titre was strongly positive in another). The remaining two carcinomas were associated with colloid degeneration. One of the occult carcinomas was associated with thyroiditis.

The cytological and histological findings are compared in table II. In nine cases (12\%) aspiration cytology was unsatisfactory. In three cases a cytological diagnosis of malignancy was made and was confirmed histologically in all. In analysing the accuracy of aspiration cytology in distinguishing neoplastic - that is, follicular adenoma together with malignancy - from non-neoplastic lesions the cytological criteria possibly neoplastic and malignant were taken together. Unsatisfactory aspirates and swellings associated with occult carcinoma were excluded.
TABLE II-Cytological predictions and histological findings in 77 removed dominant thyroid swellings

\begin{tabular}{lcccc}
\hline & \multicolumn{4}{c}{ Cytological prediction } \\
\cline { 2 - 5 } & $\begin{array}{c}\text { Non- } \\
\text { neoplastic }\end{array}$ & $\begin{array}{c}\text { Possibly } \\
\text { neoplastic }\end{array}$ & Malignant & $\begin{array}{c}\text { Un- } \\
\text { satisfactory }\end{array}$ \\
\hline Benign & 18 & 23 & 0 & 4 \\
Follicular adenoma & 8 & 8 & 0 & 5 \\
Malignant & 0 & 5 & 3 & 0 \\
Occult carcinoma & 2 & 1 & 0 & 0 \\
\hline Total & 28 & 37 & 3 & 9 \\
\hline
\end{tabular}

Of 24 removed neoplastic lesions with satisfactory cytological assessments, 16 were correctly predicted cytologically. All eight carcinomas were correctly predicted as either malignant or possibly neoplastic, but eight of 16 follicular adenomas were incorrectly predicted as non-neoplastic. Of 41 non-neoplastic lesions, 23 were incorrectly predicted as possibly neoplastic. Overall accuracy was $52 \%$.

In the 102 patients not operated on, the diagnosis, based on clinical examination, repeated cytology, and autoantibody titres, was either simple multinodular goitre or chronic lymphocytic thyroiditis. None of these patients had a possibly neoplastic picture cytologically and there were no other indications for operation. Nevertheless, at the time of analysis 46 patients were still under review with repeated aspiration cytology at the thyroid clinic and a further 19 with chronic lymphocytic thyroiditis had been registered on the Scottish Automated Follow-up Register for long term surveillance.

\section{Discussion}

It seems to be commonly accepted that the incidence of neoplasia in swellings associated with multinodularity is much lower than that in true solitary swellings. ${ }^{45}$ We acknowledge that clinical categorisation of thyroid swellings as isolated or dominant is inaccurate, given that some clinically isolated swellings are found at operation to be associated with subclinical abnormality elsewhere in the gland. Dependence on physical examination alone therefore results in underestimation of the true frequency of dominant swellings and overdiagnosis of isolated swellings. The isolated or dominant nature of thyroid swellings may be accurately established by ultrasound scanning, but our findings confirm our prejudice that this information should have little impact on management.

Despite the limitations of physical examination some $30 \%$ of discrete thyroid swellings may be so categorised as dominant rather than isolated, and on the basis of prospective study the risk of neoplasia and malignancy in such swellings is higher than expected. The frequency of neoplasia and malignancy (including three occult carcinomas) was $42 \%$ (32 cases) and $14 \%$ (11) respectively in 77 excised dominant swellings compared with $59 \%$ and $21 \%$ in 307 excised isolated swellings. ${ }^{8}$ Only $43 \%$ of dominant swellings were excised, however, compared with $78 \%$ of isolated swellings, which in itself reflects less clinical concern when swellings are dominant. With the assumption that neoplasia and malignancy had not been overlooked in patients not operated on the overall incidence of neoplasia and malignancy in dominant swellings was $18 \%$ and $6 \%$ respectively compared with $46 \%$ and $17 \%$ in isolated swellings. These figures should obviously be regarded as indicating the minimum risk of neoplasia and malignancy.

Multinodular thyroid enlargement attributable either to colloid degeneration or to chronic lymphocytic thyroiditis is common and it is not surprising that neoplasia may coexist. Our findings are therefore 
hardly unexpected, and it is more surprising that multinodularity should be taken as reassurance against the likelihood of neoplasia in any dominant area of enlargement. Malignancy in association with chronic lymphocytic thyroiditis is a particular diagnostic pitfall. The hard consistency of some malignant lesions is similar to that of a dominant area of thyroiditis. In addition, it may be difficult cytologically to distinguish between thyroiditis and lymphoma and between thyroiditis and oxyphil cell follicular neoplasm.

Although dominant swellings should clearly be regarded with greater clinical suspicion than has been traditional, the discriminant power of investigations to predict the risk of neoplasia is in general disappointing, including fine needle aspiration cytology, now widely regarded as the preferred investigation. We find that the accuracy of aspiration cytology analysed prospectively is lower than generally believed. ${ }^{8}$ The main source of error in this small series of dominant swellings was the inaccurate prediction of possible neoplasia in histologically benign swellings. We emphasise, however, that all patients with a possibly neoplastic cytological picture were operated on whereas 102 patients with non-neoplastic findings on repeated sampling were not. The true false positive rate was therefore likely to be considerably lower than might appear from this highly selected analysis. In addition, although eight of 24 neoplastic lesions were incorrectly predicted as non-neoplastic, these were histologically benign follicular adenomas, and all eight carcinomas (and one of three occult carcinomas) were correctly predicted as either malignant or possibly neoplastic.

Clearly dominant thyroid swellings cannot simply be dismissed as part and parcel of chronic lymphocytic thyroiditis or multinodular goitre, but it is not possible on the basis of this study to give clear guidelines on which should be removed. There are other factors, outlined above, apart from cytology, which influence the decision. Despite its apparent limitations, however, routine aspiration cytology has alerted us to the risks of neoplasia and malignancy in dominant swellings and, although cytological appearances influenced the decision to remove roughly four non-neoplastic dominant swellings annually, we still consider it the most valuable and only appropriate investigation.

We acknowledge financial support from the Scottish Hospitals Endowment Research Trust (SHERT) and Grampian Health Board and the facilities and advice given by the University of Aberdeen's computing centre.

1 Cole WH, Slaughter DP, Rossiter LJ. Potential dangers of non-toxic nodular goiter. ҒAMA 1945;127:883-8.

2 Cope O, Dobyns BM, Hamlin E, Hopkirk J. What thyroid nodules are to be feared. I Clin Endocrinol Metab 1949;9:1012-22. 3 Hoffman GL, Thompson NW. The solitary thyroid nodule. Arch Surg

4 Lennquist $S$. The thyroid nodule: diagnosis and surgical treatment. Surg Clin North Am 1987;67:213-32.

Beierwaltes WH. Are thyroid scans of value in evaluating most thyroid nodules? In: Thompson NW, Vinik A, eds. Endocrine surgery update. New York: Grune and Stratton, 1983:18.

6 Thomas CG, Buckwalter JA, Staab EV, Kerr CY. Evaluation of dominan thyroid masses. Ann Surg 1976;183:463-9.

7 Röher HD, Goretzki PE. Management of goiter and thyroid nodules in an area of endemic goiter. Surg Clin North Am 1987;67:233-49.

8 Cusick EL, MacIntosh CA, Krukowski ZH, Williams VMM, Ewen SWB Matheson NA. The management of isolated thyroid swellings using fine needle aspiration cytology: a prospective six year study. $B M \mathcal{F} 1990 ; 301$ : $318-21$.

9 Cusick EL, Ewen SWB, Krukowski ZH, Matheson NA. DNA aneuploidy in follicular thyroid neoplasia. Br f Surg 1991;78:94-6.

(Accepted 30 April 1991)
Department of

Epidemiology and Public

Health.University of

Dundee, Ninewells

Hospital and Medical

School, Dundee)DD1 9SY

F Forrest, PHD, research

assistant

C du V Florey, MD, professor

Department of Obstetrics and Gynaecology,

Ninewells Hospital and

Medical School, Dundee

DD1 9SY

D Taylor, MD, reader

Department of Clinica

Psychology, Royal Dundee

Liff Hospital, Liff, Angus

DD2 5NF

F McPherson, PHD, chartered

clinical psychologist

Department of Child

Health, Ninewells Hospital

and Medical School,

Dundee DD1 9SY

J A Young, FRCP, consultant

paediatrician

Correspondence to:

Professor Florey.

BMF 1991;303:22-6

\section{Reported social alcohol consumption during pregnancy and infants' development at 18 months' \\ F Forrest, C du VElorey, D Taylor, F McPherson, J A Y Young}

Abstract

Objective-To determine the relation between mothers' self reported drinking habits before, during, and after pregnancy and infants' mental and motor development at 18 months of age.

Design-Follow up study of all singleton live births born to primigravidas living in Dundee and booked into antenatal clinics from 1 May 1985 to 30 April 1986.

Setting-District of Dundee.

Subjects -846 children aged 18 months, of whom 592 attended for assessment.

Main outcome measures-Scores on Bayley scales of infant mental and motor development.

Results-For full term children, maternal alcohol consumption was not significantly related to any adverse effect on the children's mental or motor development measures at age 18 months. After confounding factors had been controlled for, alcohol consumption before pregnancy and after pregnancy was significantly related to better motor performance and mental performance.

Conclusion-Pregnant women probably need not abstain from alcohol altogether as no detectable adverse relation was found between the child's mental and physical development and the mother's weekly consumption at levels in excess of $100 \mathrm{~g}$ absolute alcohol. However, to allow for a margin of safety and taking into account the findings of an earlier phase of this study on the immediate effects on the newborn, it is recommended that pregnan women should drink no more than eight units of alcohol a week, the equivalent of about one drink a day.

\section{Introduction}

The serious effects on the offspring of excessive maternal alcohol consumption during pregnancy have been known for over 15 years. In 1973 Jones and Smith developed the term fetal alcohol syndrome to describe a cluster of signs including abnormal facial features, central nervous system dysfunction, and growth deficiency. ${ }^{1}$ Follow up studies of patients with fetal alcohol syndrome have indicated that these signs tend to persist into childhood..$^{2-4}$

The question then arose whether more moderate levels of maternal alcohol consumption during pregnancy could have smaller but nevertheless disadvantageous effects on child development. Some studies have shown adverse effects of mothers' moderate drinking on infants' mental development, ${ }^{56}$ motor development, ${ }^{57}$ behaviour, ${ }^{8-10}$ and size, ${ }^{112}$ but others have found no detectable adverse effect on moderate drinking on the development of the child. ${ }^{13-15}$

The main aim of the present study was to determine the nature of the relation between maternal alcohol consumption before, during, and after pregnancy and infant mental and motor development at 18 months, taking into account the possible con- 